\title{
Bilateral Microphthalmia and Aphakia Associated with Multiple Eye Abnormalities in a Free-Living European Red Deer Calf (Cervus elaphus)
}

\author{
Franco MUTINELLI'), Antonella VERCELLI' ${ }^{2}$, Antonio CARMINATO1)*, Lucio LUCHESA ${ }^{3)}$, Claudio PASOLLI ${ }^{4)}$, \\ Mariapia COVA $^{4)}$, Wendy MARCHIORO ${ }^{1)}$, Erica MELCHIOTTI ${ }^{1)}$ and Marta VASCELLARI ${ }^{1)}$ \\ ${ }^{1)}$ Histopathology Department, Istituto Zooprofilattico Sperimentale delle Venezie, Viale dell'Universita' 10, 35020 Legnaro (PD), Italy \\ 2) Ambulatorio Veterinario Associato, C/so Traiano 99/d, 10135 Torino, Italy \\ 3) Associazione Cacciatori Trentini, via Guardini 41, 38100 Trento, Italy \\ ${ }^{4)}$ Environment Department, Istituto Zooprofilattico Sperimentale delle Venezie, Viale dell'Universita' 10, 35020 Legnaro (PD), Italy
}

(Received 22 August 2011/Accepted 20 November 2011/Published online in J-STAGE 2 December 2011)

ABSTRACT. A free-living European red deer calf (Cervus elaphus) was euthanized due to bilateral microphthalmia. Lens was missing, replaced by proliferating squamous epithelial cells; hyperplastic squamous cells, sebaceous and mucinous glands were observed within the cornea with the characteristics of inclusion cyst. Findings were consistent with congenital microphthalmia/aphakia, with multiple eye abnormalities.

KEY WORDS: aphakia, Cervus elaphus, European red deer, eye, microphthalmia.

doi: 10.1292/jvms.11-0385; J. Vet. Med. Sci. 74(7): 527-529, 2012

In contrast to domestic and laboratory animals [11, 13, 15], congenital defects in cervid species and particularly in deer are uncommonly reported, probably due to the rapid disappearance of such animals from wild populations [1, 17]. Blindness, anophthalmia and corneal opacity [4], microphtalmia [14], ectopic intraocular lacrimal gland tissue with other ocular abnormalities [18], visual defects due to congenital abnormalities [7], true anophthalmia, congenital cystic and microphthalmic eyes with choristoma [5] were detected in free-ranging white-tailed deer (Odocoileus vinginianus). Gelmetti and others [6] reported a case of bilateral ocular dysgenesis in a 3-day-old red deer (Cervus elaphus) affected by a large intraocular dermoid cyst, bilateral microphthalmia, diffuse corneal opacity, eyelid coloboma, and conjunctival prolapse. Impaired vision due to congenital microphthalmia has also been reported in two free-living moose (Alces alces) in Canada [9]. No information is available about other cervid species.

A case of microphthalmia and aphakia associated with multiple ocular defects is described in a male 2-month-old abandoned free-living European red deer (Cervus elaphus), which was observed wandering in a natural reserve of Trento province $\left(46^{\circ} 24^{\prime} 38.93\right.$ 'N; $10^{\circ} 58^{\prime} 08.54$ 'E; altitude, $1,174 \mathrm{~m}$, north Italy). Clinically, the animal showed bilateral microphthalmia paralleled with low vitality and poor health. Since a blind deer would never reach maturity except in captivity, the euthanasia was decided.

The animal underwent complete post mortem examina-

\footnotetext{
*Correspondence to: Carminato, A., Histopathology Department, Istituto Zooprofilattico Sperimentale delle Venezie, Viale dell’Universita' 10, 35020 Legnaro (PD), Italy

e-mail: acarminato@izsvenezie.it

C2012 The Japanese Society of Veterinary Science
}

tion. Neither clinical nor pathological examination revealed further malformations of other organs. The microphtalmic eyes were removed and longitudinally sectioned. Both the eyes measured $1.4 \mathrm{~cm}$ in diameter. Gross examination revealed bilateral absence of the lens, its replacement by tissue proliferation and serous fluid effusion in the posterior ocular chamber (Fig. 1). The eyes were fixed in $10 \%$ neutral buffered formalin, routinely processed for histology, embedded in paraffin, sectioned at $4 \mu \mathrm{m}$, and stained with hematoxylin and eosin and with periodic acid-Schiff (PAS) method. Immunohistochemistry was performed on serial sections using a mouse anti-vimentin antibody (V9, DakoCytomation, Copenhagen, Denmark), a mouse anticytokeratin (AE1/AE3, DakoCytomation) and a rabbit anti S-100 protein (DakoCytomation). Antigen retrieval ( $\mathrm{pH}$ 6 buffer, DakoCytomation) was applied for cytokeratin. The detection system EnVision ${ }^{\mathrm{TM}}$ PX Dual Link System (DakoCytomation) at RT was used, 3,3-diaminobenzidine (DAB plus, DakoCytomation) for vimentin and 3-Amino9-ethylcarbazole (AEC, Sigma, St. Louis, MO, U.S.A.) for cytokeratin and S-100 protein were used as chromogens. Sections were counterstained with Carazzi/Mayer hematoxylin and mounted with Eukitt ${ }^{\circledR}$ (Bio-optica, Milano, Italy).

The eyes were examined histopathologically through multiple seriate sections, to make sure that remnant lens material or other apparently missing eye structures were not missed at interpretation due to plane of section. Multiple abnormalities were observed in both eyes: the lens were not present and replaced by a proliferation of epithelial cells with squamous metaplasia and multiple foci of mucinous glands as confirmed by positive reaction to cytokeratin on immunohistochemistry and PAS stain, respectively. The proliferating epithelial tissue seemed merging with the non-pigmented ciliary epithelium (Fig. 2). The 


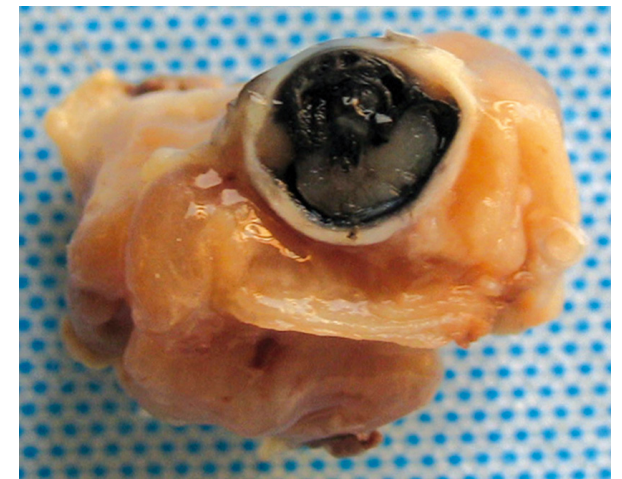

Fig. 1. Eye; red deer. Longitudinal section of the microphtalmic eye revealed no lens replaced with tissue proliferation accompanied by retinal detachment.

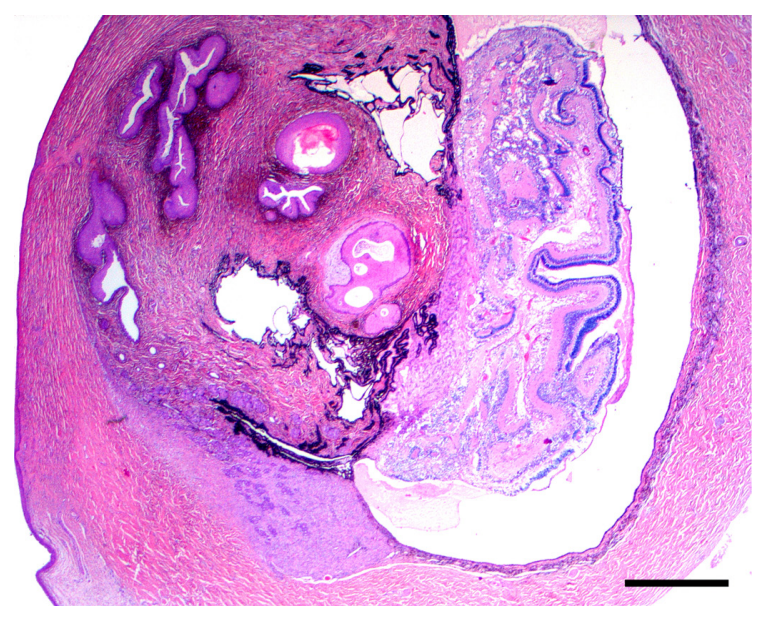

Fig. 2. Eye; red deer. The lens was not present and replaced by a proliferation of epithelial cells with squamous differentiation and multiple foci of mucinous glands merging with the non pigmented epithelium of ciliary epithelium. HE. $\operatorname{Bar}=680 \mu \mathrm{m}$.

abundant stroma composed of spindle cells surrounding the epithelial cords and tubules was positive for vimentin and negative for S100 protein. The Descemet's membrane and the iris were not present. The iridocorneal angle was absent. A cyst containing keratin lamellae (multiloculated cyst) composed of hyperplastic multilayered squamous epithelial cells with sebaceous glands differentiation was embedded within a stromal tissue (Fig. 3). The presence of PAS positive mucinous glands associated with the stratified epithelium could be interpreted as possible conjunctival inclusion cyst (Fig. 3). Signs of retinal disorganization with retinal folding (retinal dysplasia) were observed; rosettes were not detected. In particular, abundant eosinophilic proteinaceous material was present between the pigmented epithelium and the photoreceptor layer (serous detachment). The photoreceptor layer showed the presence of edema and photoreceptor disarrangement, while the layer composed of

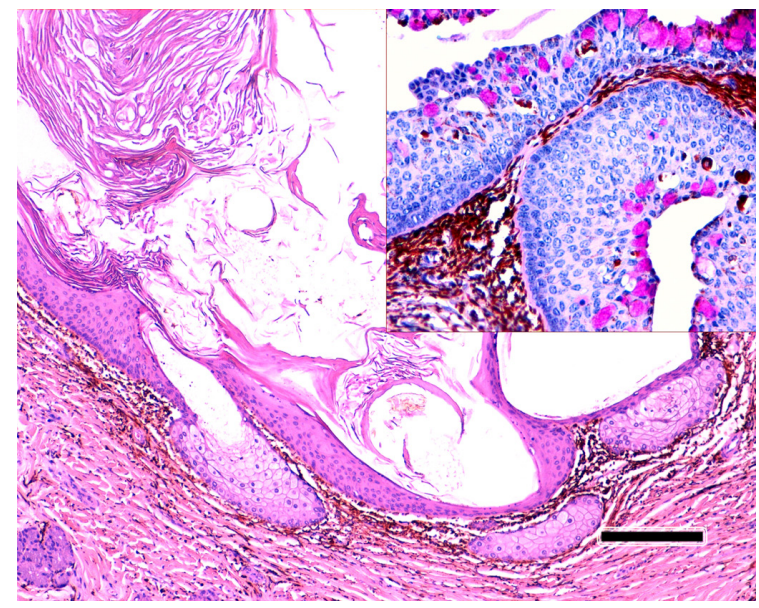

Fig. 3. Eye; red deer. Hyperplastic multilayered squamous epithelial cells embedded in the corneal stroma generating an epithelial inclusion cyst containing keratin lamellae (multiloculated cyst). HE. Bar $=200 \mu \mathrm{m}$. Inset: detail of mucinous glands (possible conjunctival inclusion cyst) showing strong PAS positive cytoplasmic reaction. PAS stain.

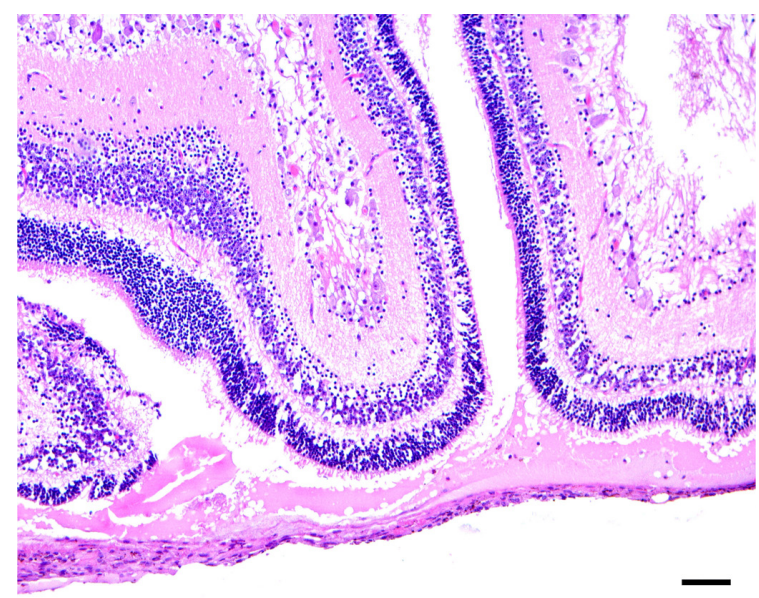

Fig. 4. Eye; red deer. Retinal detachment and folding with signs of disorganization were observed. Eosinophilic proteinaceous material accumulated between the pigmented epithelium and the photoreceptor layer (serous detachment). HE. Bar $=100 \mu \mathrm{m}$.

bipolar and ganglion cells did not show abnormalities (Fig. 4).

Congenital ocular abnormalities have been occasionally described in cervid species and little is known about the etiology of this anomalous development $[1,5,14,17]$. Microphthalmia has also been described in the white-tailed deer [5, 7, 14]. A case of bilateral ocular dysgenesis in a 3-day-old red deer (Cervus elaphus) affected by bilateral microphthalmia (1.5 $\mathrm{cm}$ in diameter), dermoid cyst, diffuse corneal opacity, eyelid coloboma at the nasal cantus, conjunctival prolapse without conjunctival secretion was recently reported in north Italy [6]. The histological find- 
ings reported by Gelmetti and others [6] appeared similar to microphthalmia described in human patients [16].

Microphthalmia may be resulted from involution of the primary optic vesicle and failure of the fetal cleft to close (colobomatous microphtalmia) or abnormality in the development of the ectodermal surface leading to failure of lens formation. In case the fissure eventually closes, it may be difficult to distinguish between colobomatous and noncolobomatous microphtalmia. In most cases, however, microphtalmia occurs through a combination of cellular deficiency within the optic vescicle/cup compounded by failure of the optic fissure to close on schedule. Aphakia is considered a rare condition and may occur through failure of contact between the optic vescicle and the surface ectoderm during the period when the surface ectoderm responds to its inductive influences [3]. This early aphakia would be associated with anterior segment dysgenesis, as observed in this case, where no cornea, iridocorneal angle and iris were recognized. Chromosomal abnormality and exposure to toxic substances have been hypothesized as possible causes of ocular anomalies in cervids [5]. In cattle, bovine viral diarrhea virus infection and deficiency or excess of vitamin A are reported to be causes of ocular malformations [13]. In different species, including human beings, epithelial inclusion cysts are reported to be congenital or traumatic in origin $[2,12]$. Corneal epithelial inclusion cyst in the canine species is generally reported as a unilateral, single, round mass that is generally not associated with other ocular anomalies [8]. In the present case, a post-traumatic origin of the lesion was considered unlikely because of no signs of corneal perforation were detected and both eyes showed the same ocular abnormalities. Similar conclusion made by Schulze et al. [13] regarding the probable cause of the ocular aphakia in a calf was taken into consideration to explain the findings here reported. Particularly, the exclusion of environmental causes and the low inbreeding coefficient similarly hypothesized for a wild animal draw to consider hereditary etiology as the most probable [13]. In our case, a deficiency or excess of vitamin A was considered unlikely in a free-living population, since primary vitamin A deficiency usually occurs in housed animals fed a ration containing little or no green forage [10]. Environmental toxic causes for these malformations of the eyes could not be excluded, because no further affected animals belonging to the same population was found, according to the monitoring performed by game wardens.

In the present case, the young age of the affected red deer and the bilateral presentation are rather indicative of congenital eye abnormalities in a free-living European red deer calf (Cervus elaphus). The similar report described by Gelmetti et al. [6] in a brief period and in two close geographical areas could further support the need for a continuing monitoring of wild animal population, in order to improve our knowledge about less relevant pathological entities and their possible correlation with the environment.

\section{REFERENCES}

1. Barrett, M. W. and Chalmers, G. A. 1975. Congenital anomalies in a neonatal white-tailed deer in Alberta. J. Wildl. Dis. 11: 497-501. [Medline]

2. Bedford, P. G. C., Grierson, I. and McKechnie, N. M. 1990. Corneal epithelial inclusion cyst in the dog. J. Small Anim. Pract. 31: 64-68. [CrossRef]

3. Cook, C. S. 1995. Embryogenesis of congenital eye malformations. Vet. Comp. Ophtalm 5: 109-123.

4. Dahlberg, B. L. and Guettinger, R. C. 1956. The white-tailed deer in Wisconsin. p. 14. In: Technical Wildlife Bull., 1st ed., Wisconsin Conservatory Department, Wisconsin.

5. Fulton, A. B., Albert, D. M., Buyukmihci, N., Wyand, D. S. and Stone, W. B. 1977. Spontaneous anophthalmia and microphthalmia in white-tailed deer. J. Comp. Pathol. 87: 557568. [Medline] [CrossRef]

6. Gelmetti, D., Bertoletti, I. and Giudice, C. 2010. Bilateral complex microphthalmia with intraocular dermoid cyst in a neonate red deer (Cervus elaphus). J. Wildl. Dis. 46: 961-965. [Medline]

7. Howard, D. R., Krehbiel, J. D., Fay, L. D., Stuht, J. N. and Whitenack, D. L. 1976. Visual defects in white-tailed deer from Michigan: six case reports. J. Wildl. Dis. 12: 143-147. [Medline]

8. Koch, S. A., Langloss, J. M. and Schmidt, G. 1974. Corneal epithelial inclusion cysts in four dogs. J. Am. Vet. Med. Assoc. 164: 1190-1191. [Medline]

9. Kuiken, T., Grahn, B. and Wobeser, G. 1997. Pathology of ocular lesions in free-living moose (Alces alces) from Saskatchewan. J. Wildl. Dis. 33: 87-94. [Medline]

10. Mason, C. S., Buxton, D. and Gartside, J. F. 2003. Congenital ocular abnormalities in calves associated with maternal hypovitaminosis A. Vet. Rec. 153: 213-214. [Medline] [CrossRef]

11. Priester, W. A. 1972. Congenital ocular defects in cattle, horses, cats, and dogs. J. Am. Vet. Med. Assoc. 160: 1504-1511. [Medline]

12. Reed, J. W. and Dohlman, C. H. 1971. Corneal cysts: a report of 8 cases. Arch. Ophthalmol. 86: 648-652. [Medline] [CrossRef]

13. Schulze, U., Kuiper, H., Schmidtbauer, S., Wohlsein, P., Krause, A., Haas, L. and Distl, O. 2006. Aphakia in a German Holstein calf. Dtsch. Tierarztl. Wochenschr. 113: 355-357. [Medline]

14. Stone, W. B., Hesselton, W. I. and Palmateer, J. T. 1970. Microphthalmia in a white-tailed deer. N. Y. Fish Game J. 17: 133-134.

15. Szabo, K. T. 1989. p. 315. Congenital Malformations in Laboratory and Farm Animals, Academic Press, San Diego.

16. Verma, A. S. and Fitzpatrick, D. R. 2007. Anophthalmia and microphthalmia. Orphanet J. Rare Dis. 2: 47-54. [Medline] [CrossRef]

17. Wobeser, G. and Runge, W. 1973. Multiple anomalies in a white-tailed deer fetus. J. Wildl. Dis. 9: 356-358. [Medline]

18. Wyand, D. S., Lehav, M., Albert, D. M. and Stone, W. B. 1972. Intraocular lacrimal gland tissue with other ocular abnormalities occurring in a white-tailed deer. J. Comp. Pathol. 82: 219221. [Medline] [CrossRef] 